\title{
Rootstock Influences Changes in Ion Concentrations, Growth, and Photosynthesis of 'Hass' Avocado Trees in Response to Salinity
}

\author{
Michael V. Mickelbart ${ }^{1}$ and Mary Lu Arpaia ${ }^{2}$ \\ Department of Botany and Plant Sciences, University of California, Riverside CA 92521
}

\begin{abstract}
ADDITIONAL INDEX WORDs. shoot growth, leaf necrosis, sodium, chloride, Persea americana
Abstract. Effect of salinity $\left(1.5,3.0,4.5\right.$, or $\left.6.0 \mathrm{dS} \cdot \mathrm{m}^{-1}\right)$ on growth and physiology of 1-year-old 'Hass' avocado (Persea americana Mill.) trees on one of three rootstocks, 'Thomas', 'Toro Canyon', or 'Duke 7', was investigated to determine the relative salinity tolerance of these rootstocks and to determine possible reasons for any observed differences in tolerance. Leaves of trees on 'Thomas' rootstock had the highest leaf $\mathrm{Na}^{+}, \mathrm{Cl}^{-}$, and necrosis compared to trees on the other two rootstocks. Exposure to salinity resulted in decreased growth of shoots on all rootstocks, but was greatest on 'Thomas' and least on 'Duke 7'. The oldest leaves on all rootstocks had the highest proportion of leaf necrosis, whereas younger leaves exhibited almost no necrosis. Salinity reduced net $\mathrm{CO}_{2}$ assimilation (A) and chlorophyll concentrations of scion leaves on all rootstocks, but more in older leaves than in younger leaves. Although the effects of salinity on A were greater for trees on 'Thomas' on one measurement date, overall, rootstock differences in A were not significant for any leaf age. Differences in response to salinity among rootstocks were noted primarily in morphological traits such as growth and leaf necrosis, rather than physiological traits such as gas-exchange and water relations. Based on overall growth and physiological response to salinity, trees on 'Thomas' performed poorest, whereas trees on 'Duke 7' exhibited the greatest salt tolerance. The relative tolerance of the various rootstocks appeared to be due primarily to their ability to exclude $\mathrm{Na}^{+}$ and $\mathrm{Cl}^{-}$from the scion.
\end{abstract}

Avocado (Persea americana Mill.) is an important fruit crop in tropical and subtropical areas. Although it is classified as salt sensitive among fruit crops (Maas, 1986), avocado is often grown where irrigation water contains significant amounts of soluble salts (Branson and Gustafson, 1972). Accumulation of salts in the root zone has been correlated with reductions in avocado tree volume (Kalmar and Lahav, 1977) and fruit yield (Lahav and Kalmar, 1977). Therefore, rootstock differences in salt tolerance have important implications for avocado growers.

Although avocado rootstocks have been selected primarily for tolerance to avocado root rot (Phytophthora cinnamomi Rands), they have also been selected for salinity tolerance (Haas, 1950a; Embleton et al., 1961; Oster and Arpaia, 1992). Studies have shown that avocado salt tolerance, defined as the ability to maintain growth in saline environments, is greatest in trees grown on West Indian rootstock races and poorest on Mexican rootstocks, with Guatemalan rootstocks exhibiting intermediate responses (Ben-Ya'acov, 1970; Gustafson et al., 1970). In subtropical areas subject to winter frosts such as California, however, West Indian rootstocks have not been utilized because of their poor cold tolerance. It would be advantageous to the California avocado industry to identify rootstocks that have the salinity tolerance often observed in West Indian races, but that are able to tolerate some degree of frost.

It is well known that rootstocks can impart stress tolerance to the scion and that the beneficial effect of the rootstock is often the exclusion of $\mathrm{Na}^{+}$and/or $\mathrm{Cl}^{-}$from the scion. This has been

Received for publication 2 Aug. 2000. Accepted for publication 21 Mar. 2002. This project was funded in part by a grant-in-aid from the California Avocado Commission. The authors wish to thank Gene Maas and the late Leland Francois for invaluable suggestions and assistance; Phoebe Welburn for technical assistance throughout the project; and Stacey Ontai, Steve Reints, Paul Robinson, and David Stottlemyer for assistance in the final data collection.

${ }^{1}$ Current address: Plant Sciences Group, Soil, Plant and Ecological Sciences Division, P.O. Box 84, Lincoln University, Canterbury 8150, New Zealand.

${ }^{2}$ Corresponding author: Batchelor Hall Extension, University of California, Riverside, CA 92521. demonstrated clearly in citrus (Citrus L. sp.) (Banuls et al., 1990). While there appears to be a correlation between leaf $\mathrm{Na}^{+}$or $\mathrm{Cl}^{-}$ concentrations and physiological responses to salinity in some citrus rootstock-scion combinations (Lloyd et al., 1987), the two factors are not always related (Banuls and Primo-Millo, 1995). Avocado rootstocks have been shown to affect scion concentrations of both $\mathrm{Na}^{+}$and $\mathrm{Cl}^{-}$(Ben-Ya'acov, 1970; Oster and Arpaia, 1992). Understanding the relationship between $\mathrm{Na}^{+}$and/or $\mathrm{Cl}^{-}$ uptake and scion performance will help in screening for suitable rootstocks for areas such as southern California or Israel, where soil salinity levels can be high.

In this study, two Mexican rootstocks ('Thomas' and 'Duke 7') and a Mexican-Guatemalan hybrid rootstock ('Toro Canyon') were evaluated. These three rootstocks account for $\approx 75 \%$ of the clonal rootstocks currently produced commercially in California (L. S. Rose, Brokaw Nursery, Saticoy, Calif., personal communication). The objectives of this investigation were to 1) evaluate the relative salt tolerance of the three most commercially important avocado rootstocks used currently in California, and 2) determine if exclusion of $\mathrm{Na}^{+}$and/or $\mathrm{Cl}^{-}$from the above-ground portions of the plant is the primary mechanism of salt tolerance in avocado.

\section{Materials and Methods}

Scions of 'Hass' avocado were grafted onto one of three clonally produced (Whitsell et al., 1989) rootstocks, 'Thomas' (TH), 'Toro Canyon' (TC), or 'Duke 7' (D7). Following grafting, trees were maintained under commercial field conditions in soil for 1 year in 10-L polyethylene containers. The mean trunk crosssectional area (TCA) of trees at the beginning of the study was $10.2 \mathrm{~cm}^{2}$ with no significant differences among rootstock-scion combinations.

Trees were removed carefully from the containers on 3 May 1994, the soil was gently washed from the roots and the trees were planted in outdoor sand tanks at the U.S. Department of Agricul- 
ture, Agricultural Research Service, Salinity Laboratory, Riverside, Calif. Two trees of each rootstock were planted in each of twenty $1.5 \mathrm{~m}^{3}$ concrete tanks ( 40 trees per rootstock and six trees per tank) filled with silica sand. This date was $72 \mathrm{~d}$ before the establishment of the salinity treatments on day 0 . Mean daily high and low temperatures during the experiment (day -72 to day 80 ) were $31.0 \pm 5.3$ and $15.9 \pm 3.0^{\circ} \mathrm{C}$, respectively and mean high and low relative humidity during the experiment was $65.1 \pm 6.6$ and $36.8 \pm 9.4 \%$, respectively. No significant rainfall occurred during the investigation.

Trees were fertigated four times daily with half-strength Hoagland's nutrient solution (Hoagland and Arnon, 1950). The solution was pumped from $1.6 \mathrm{~m}^{3}$ underground tanks (one holding tank for each sand tank) into the sand tanks and drained back into the holding tanks after passing through the root zone of the plants. Electrical conductivity (EC) of the water (containing the base nutrient solution) before addition of the salt was $1.3 \mathrm{dS} \cdot \mathrm{m}^{-1}$. Salinity was increased using $\mathrm{NaCl}$ and $\mathrm{CaCl}_{2}$ in equal molar portions to obtain salt levels of $1.5,3.0,4.5$, and $6.0 \mathrm{dS} \cdot \mathrm{m}^{-1}$. The lowest EC used in this experiment was 1.5 to allow for a welldefined and consistent EC level in the lowest treatment level. Salinity treatments were initiated on 11 July (day 3). Salinization of the root zone was established in a stepwise manner, increasing $1.5 \mathrm{dS} \cdot \mathrm{m}^{-1} \cdot \mathrm{d}^{-1}$. The day on which all tanks were receiving the appropriate salt solutions (14 July) was designated day 0. ECs of the treatment solutions were monitored and adjusted accordingly throughout the study to insure consistent salinity levels.

Avocado trees accumulate biomass during growth flushes, which are periods of rapid shoot extension and leaf production that occur one to several times per year (Arpaia et al., 1995; Whiley et al., 1988). The trees in this experiment exhibited two growth flushes during the study. One flush began before initiation of the treatments (about day 10) and ended shortly after treatment initiation (about day 22). Another growth flush occurred between days 38 and 65 . The growth flushes of the trees were in synchrony across all treatments. To determine the influence of salinity on leaves of various ages, leaves were categorized into three age groups dependent upon the growth flush in which they emerged. Flush 1 (F1) leaves were fully mature before initiation of the salt treatments, flush 2 (F2) leaves were emerging at initiation of the treatments, and flush 3 (F3) leaves emerged subsequent to initiation of the treatments (about day 38) (F3). When final measurements were made, F1 and F2 leaves were fully expanded and mature, whereas F3 leaves were fully expanded but not yet fully mature based on visual assessment (Schaffer et al., 1991; M.L. Arpaia, unpublished observations).

Shoot extension was measured by tagging five branches per tree at the beginning of the experiment (day 0) and measuring branch length every 2 weeks (final measurement was on day 72). Trunk diameter was measured $2 \mathrm{~cm}$ above the graft union of each tree using calipers on 6 July (day 8) and again on 20 Sept. (day 72). TCA was calculated as $\mathrm{pr}^{2}$ and the difference of beginning and ending measurements $(\triangle \mathrm{TCA})$ was calculated.

Net $\mathrm{CO}_{2}$ assimilation rate (A) was measured using an open gas-exchange system (Analytical Development Co., Ltd., Hoddeson, United Kingdom). Mean photosynthetically active radiation $(P A R)$ during A measurements was $1240 \mathrm{mmol} \cdot \mathrm{m}^{-2} \cdot \mathrm{s}^{-1}$ and was never $<900 \mu \mathrm{mol} \cdot \mathrm{m}^{-2} \cdot \mathrm{s}^{-1}$. Preliminary measurements were made throughout the light period several times during the week before initiation of the treatments to determine the time of day for highest A. Based on this, measurements were made during midday throughout the study. Measurements were made on F1 and F2 leaves approximately every 2 weeks throughout the experimental period and on F1, F2, and F3 leaves at the end of the experimental period (day 73). For each measurement, two leaves of each leaf type per tree were chosen at random and used for measurements. Following A measurements of F1, F2, and F3 leaves on day 73 , the same leaves were removed for determination of chlorophyll concentration. Chlorophyll was extracted

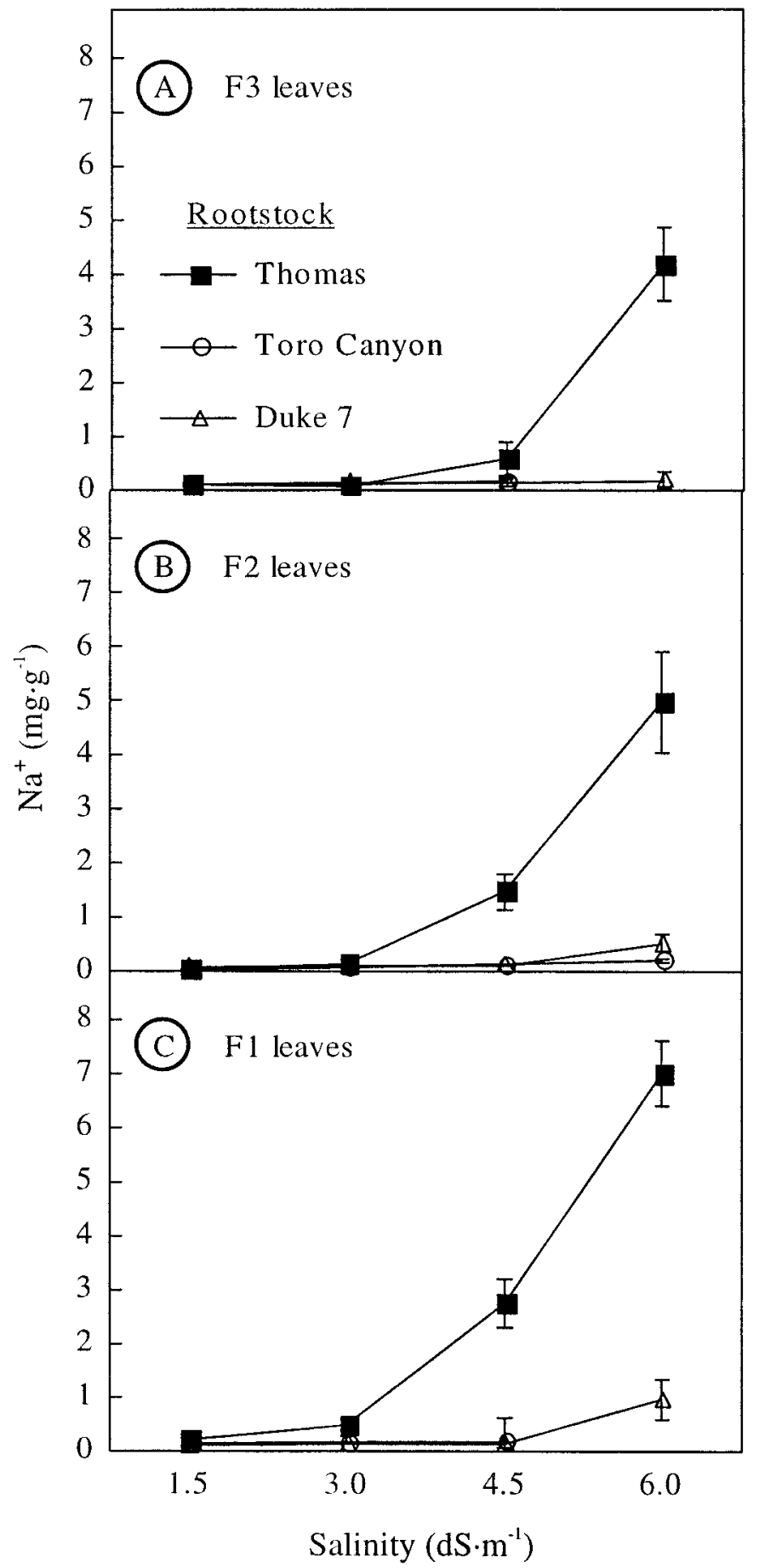

Fig. 1. Sodium ion concentrations of (A) F3, (B) F2, and (C) F1 leaves of 'Hass' avocado trees on 'Thomas', 'Toro Canyon', or 'Duke 7' rootstocks exposed to one of four salinity levels [1.5 (control), 3.0, 4.5 or $\left.6.0 \mathrm{dS} \cdot \mathrm{m}^{-1}\right]$ for $80 \mathrm{~d}$. Each symbol represents the mean of five replications and two subsamples per replication. Vertical bars represent SE values. Samples for F1 and F3 leaves of trees on 'Toro Canyon' were too small for accurate measurements of $\mathrm{Na}^{+}$ concentrations and are therefore not presented. 
from freeze-dried leaf tissue using the method of Bruinsma (1963). Also on day 73, two leaves of each of three shoot growth flushes (F1, F2, and F3) were harvested from each tree for measurements of leaf area and leaf necrosis. Leaf area was measured with an area meter (LI-3100; LI-COR, Inc., Lincoln, Nebr.). The entire area of each leaf and the area of the leaf after removing any necrotic portion were obtained and percentage necrosis was calculated as (necrotic area/total leaf area) $\times 100$.

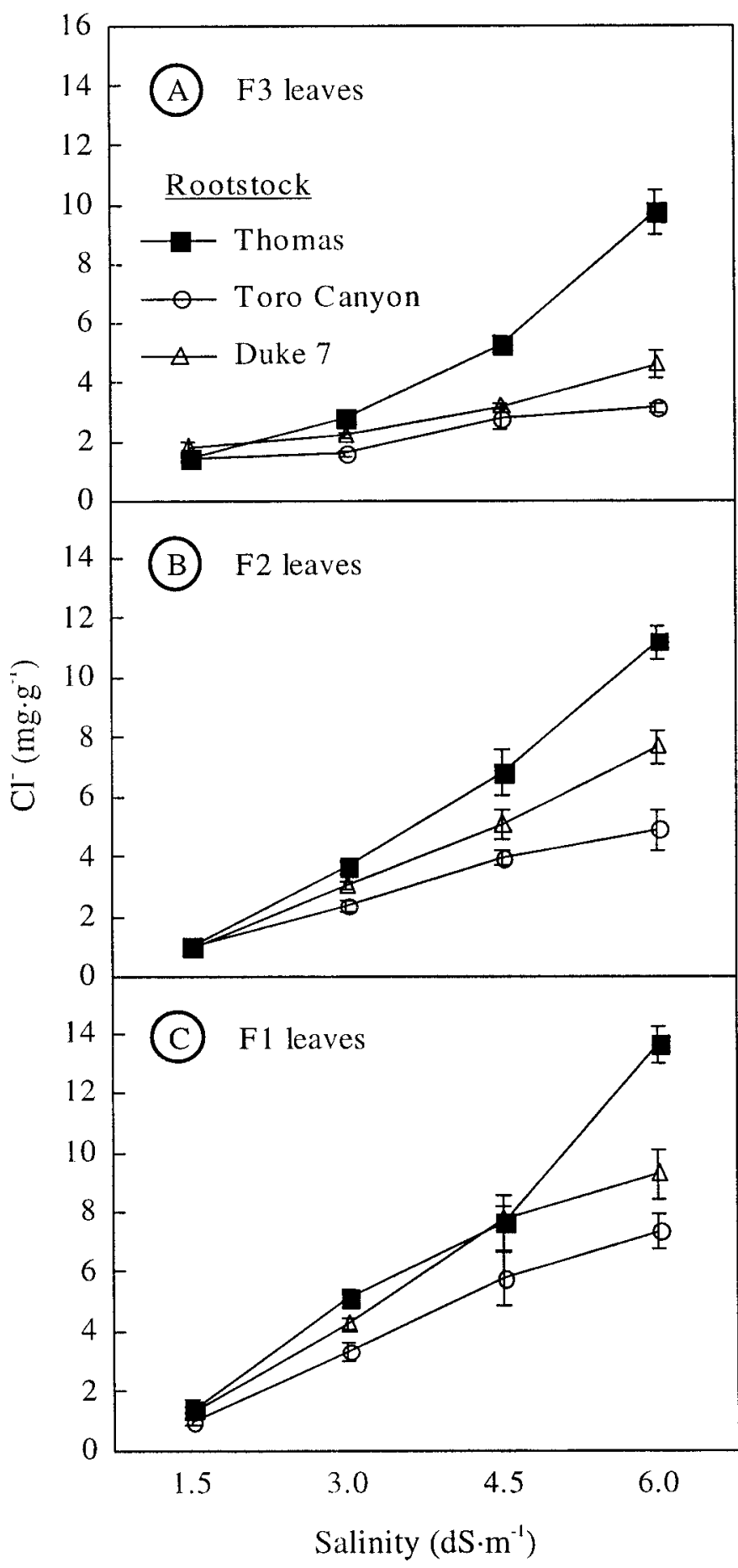

Fig. 2. Chloride ion concentrations of (A) F3, (B) F2, and (C) F1 leaves of 'Hass' avocado trees on 'Thomas', 'Toro Canyon', or 'Duke 7' rootstocks exposed to one of four salinity levels [1.5 (control), 3.0, 4.5 or $\left.6.0 \mathrm{dS} \cdot \mathrm{m}^{-1}\right]$ for $80 \mathrm{~d}$. Each symbol represents the mean of five replications and two subsamples per replication. Vertical bars represent SE values.
Plants were removed from the tanks on day 80 and separated into shoot tips (terminal $2 \mathrm{~cm}$ of each shoot), leaves of each age category (F1, F2, and F3), stems, upper trunk ( 2 to $4 \mathrm{~cm}$ above the graft union), lower trunk ( 2 to $4 \mathrm{~cm}$ below the graft union), and roots. Plant parts were rinsed in distilled water, dried in a forcedair chamber, and ground through a 40 -mesh $(0.635-\mathrm{mm})$ screen. Ion concentrations were determined by dry ashing, followed by atomic emission analysis $\left(\mathrm{Na}^{+}\right.$and $\left.\mathrm{K}^{+}\right)$(Jones, 1984) or titration with silver nitrate $\left(\mathrm{Cl}^{-}\right)$(Frankenberger et al., 1984).

The experimental design was a split plot with five tanks (blocks) for each of the salinity levels and two trees (subsamples) of each rootstock within each tank. In some cases (where data collection was labor-intensive), only four of the five replicates (randomly selected) were used. When only four replicates were used, the same four replicates were used for all measurements. All data were subjected to analysis of variance procedures, using salt level, rootstock, and leaf age where appropriate, as the independent factors (SAS Inst., Inc., 1985).

\section{Results and Discussion}

IONIC CONCENTRATIONS. In general, leaves on TH had higher $\mathrm{Na}^{+}$than leaves on the other rootstocks, although this was especially true as salinity level and leaf age increased (Fig. 1). Fully mature (F2) leaves of trees on $\mathrm{TH}$ had a $\mathrm{Na}^{+}$concentration 22 and 10 times that of leaves on TC and D7 rootstocks, respectively, at the highest salinity level, and the increase in leaf $\mathrm{Na}^{+}$with increasing salinity was greatest on TH (Fig. 1). This supports earlier assessments of Oster and Arpaia (1992), who showed that trees on $\mathrm{TH}$ accumulated much higher concentrations of $\mathrm{Na}^{+}$ions than trees on TC or D7 when exposed to high salinity levels. Sodium concentration did not increase with increased salinity in leaves on TC, whereas leaves of trees on D7 had a Na+ concentration only slightly greater than TC at the highest salinity level. Leaf $\mathrm{Cl}^{-}$increased linearly with increasing salinity in trees on all rootstocks (Fig. 2). TH had the highest leaf $\mathrm{Cl}^{-}$, which is characteristic of Mexican rootstocks (Embleton et al., 1955; Haas, 1952; Kadman, 1958). This research also confirms previous studies that have demonstrated that avocado trees take up $\mathrm{Cl}^{-}$rapidly (Chirachint and Turner, 1988) and in proportion to substrate levels (Bingham and Fenn, 1966). While increases in $\mathrm{Na}^{+}$were slight or nonexistent with an increase in salinity level from 1.5 to $3.0 \mathrm{dS} \cdot \mathrm{m}^{-1}, \mathrm{Cl}^{-}$increased linearly with salinity level. Among the three rootstocks used in this experiment, there were no apparent differences in this trait.

Sodium increased in roots and lower trunk sections (below the graft union) with increasing salinity, but did not differ among rootstocks (data not presented). Thus, exclusion of $\mathrm{Na}^{+}$from avocado leaves was not related to the amount of $\mathrm{Na}^{+}$ions stored in the root, but rather the movement of $\mathrm{Na}^{+}$ions through the graft union and into the stems. However, in trunk sections above the graft union and in stems, $\mathrm{Na}^{+}$was highest in trees on $\mathrm{TH}$. This correlated with higher leaf $\mathrm{Na}^{+}$in trees on TH (Fig. 1). A different pattern was observed with regard to $\mathrm{Cl}^{-}$. Similar to $\mathrm{Na}^{+}, \mathrm{Cl}^{-}$ increased with increasing salinity in roots $\left(6.1\right.$ to $8.9 \mathrm{mg} \cdot \mathrm{g}^{-1}$ for all three rootstocks in the 1.5 to $6.0 \mathrm{dS} \cdot \mathrm{m}^{-1}$ treatments, respectively), with no differences among rootstocks (data not presented). However, there were no significant differences in increases in trunk $\mathrm{Cl}^{-}$below or above the graft union among rootstocks, and $\mathrm{Cl}^{-}$ increased only slightly with salinity in these organs (from 1.1 to 1.6 and 1.3 to $1.9 \mathrm{mg} \cdot \mathrm{g}^{-1}$ in trunk sections below and above the graft union, respectively). 
Both $\mathrm{Na}^{+}$and $\mathrm{Cl}^{-}$increased with increased leaf age in all rootstocks within a given salinity level (Figs. 1 and 2). This relationship between leaf age and ion concentration has been reported previously in avocado (Haas, 1950c). Although salt ion concentration increased with leaf age, the shoot tips contained higher concentrations of $\mathrm{Na}^{+}$and $\mathrm{Cl}^{-}$ions than leaves (Fig. 3). The shoot tips of trees on $\mathrm{TH}$ had higher $\mathrm{Na}^{+}$and $\mathrm{Cl}^{-}$than TC or D7. This confirms earlier observations on these rootstocks by Oster and Arpaia (1992). Shoot tip $\mathrm{Na}^{+}$appears to be a good indicator of impending salinity damage, and may prove to be a useful tool in screening large numbers of plants.

Short-term exposure to salinity can markedly reduce avocado shoot growth (Chirachint and Turner, 1988; Wiesman, 1995), but the rootstock has been shown to affect the degree to which avocado shoot growth is reduced under salinity (Downton, 1978; Oster et al., 1985). Growth rates of trees on all rootstocks were reduced during an active growth flush (between days 38 and 65) by high salinity (data not presented), resulting in a reduction in shoot length over the experimental period (Fig. 4). During this flush, the growth rate of trees exposed to the highest salinity level was reduced to $26 \%, 82 \%$, and $72 \%$ of the control in trees on TH, $\mathrm{TC}$, and D7 rootstock, respectively. Trees on D7 rootstock were more vigorous overall than trees on the other two rootstocks.

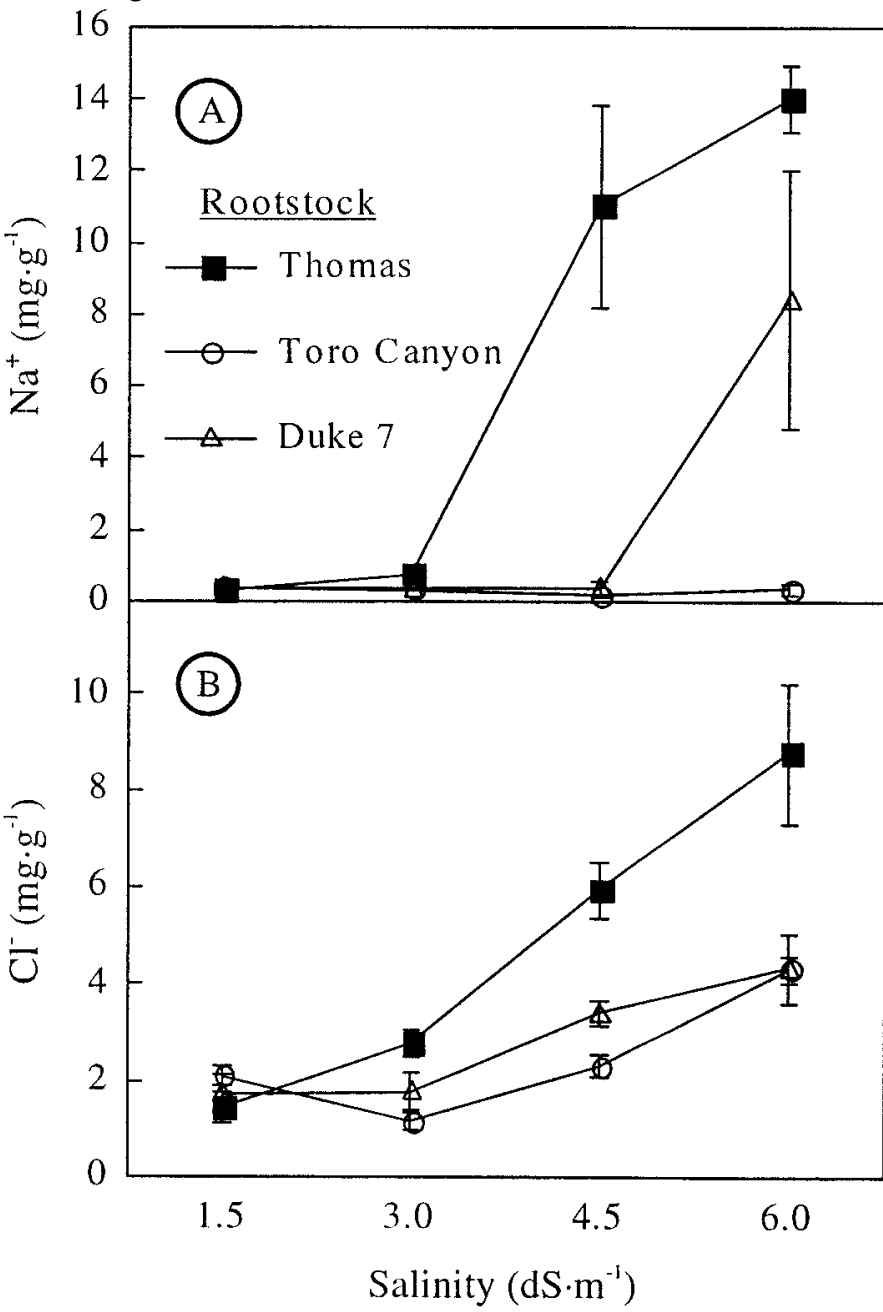

Fig. 3. (A) Sodium and (B) $\mathrm{Cl}^{-}$ion concentrations of shoot tips of 'Hass' avocado trees on 'Thomas', 'Toro Canyon', or 'Duke 7' rootstocks exposed to one of four salinity levels [1.5 (control), 3.0, 4.5 or $\left.6.0 \mathrm{dS} \cdot \mathrm{m}^{-1}\right]$ for $80 \mathrm{~d}$. Each symbol represents the mean of four replications and two subsamples per replication. Vertical bars represent SE values.
Shoot extension and leaf area of D7 were not affected by lower salinity levels, whereas TH and TC shoot length and leaf area were decreased by all levels of salinity $>1.5 \mathrm{dS} \cdot \mathrm{m}^{-1}$. Trees on TH displayed the greatest reduction (50\%) in shoot extension over the course of the experiment in response to increased salinity. Salinity-induced TCA decreases were similar for all rootstocks. Exposure of trees to $1.5,3.0,4.5$, and $6.0 \mathrm{dS} \cdot \mathrm{m}^{-1}$ for $72 \mathrm{~d}$ resulted in $\triangle$ TCA of $3.82,2.78,1.80$, and $1.09 \mathrm{~cm}^{2}$, respectively.

Although trees on D7 had larger leaves than those on the other rootstocks, individual leaf area was reduced to similar degrees ( $80.1 \%$ to $85.8 \%$ ) by salinity in all rootstocks (Fig. 4). Moore and Richards (1946) showed that reduced leaf size in avocado was related more to soil moisture than to salinity. However, the observed reduction in leaf area in response to salinity observed in this study does not appear to be a result of decreased water availability. Midday leaf relative water content decreased only slightly with salinity and was not correlated with leaf area (data not presented). Whole-plant reductions in leaf area in response to salinity were observed in TH, from which more leaves abscised than from either of the other rootstocks (visual observations).

Leaf age had a significant effect on the amount of salinityinduced necrosis (Fig. 5). The oldest sampled leaves (F1) exhib-

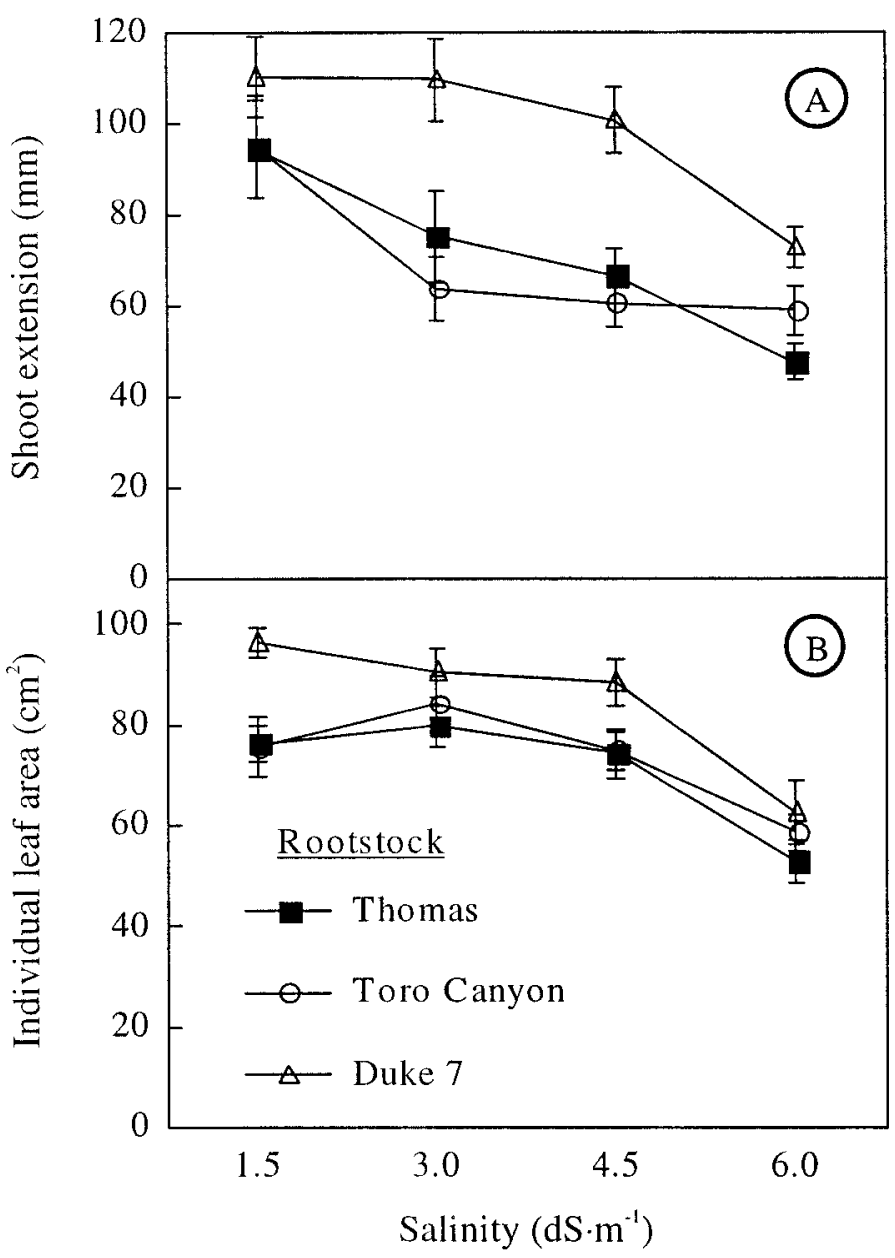

Fig. 4. (A) Shoot extension and (B) individual leaf area of F2 leaves of 'Hass' avocado trees on 'Thomas', 'Toro Canyon', or 'Duke 7' rootstocks exposed to one of four salinity levels [1.5 (control), 3.0, 4.5 or $\left.6.0 \mathrm{dS} \cdot \mathrm{m}^{-1}\right]$ for $72 \mathrm{~d}$. Each symbol represents the mean of five replications and five subsamples per replication (shoot extension) or four replications and two subsamples per replication (leaf area). Vertical bars represent SE values. 
ited the greatest level of necrosis, whereas younger leaves (F2) were less necrotic. This occurred in spite of the fact that leaves from these two flushes were exposed to salinity for the same amount of time. F3 leaves, which developed after initiation of the stress, showed few signs of leaf necrosis with the exception of the $\mathrm{TH}$ rootstock at $6.0 \mathrm{dS} \cdot \mathrm{m}^{-1}$, in which $3 \%$ of the leaf area was affected. Within each leaf age group, the greatest increase in

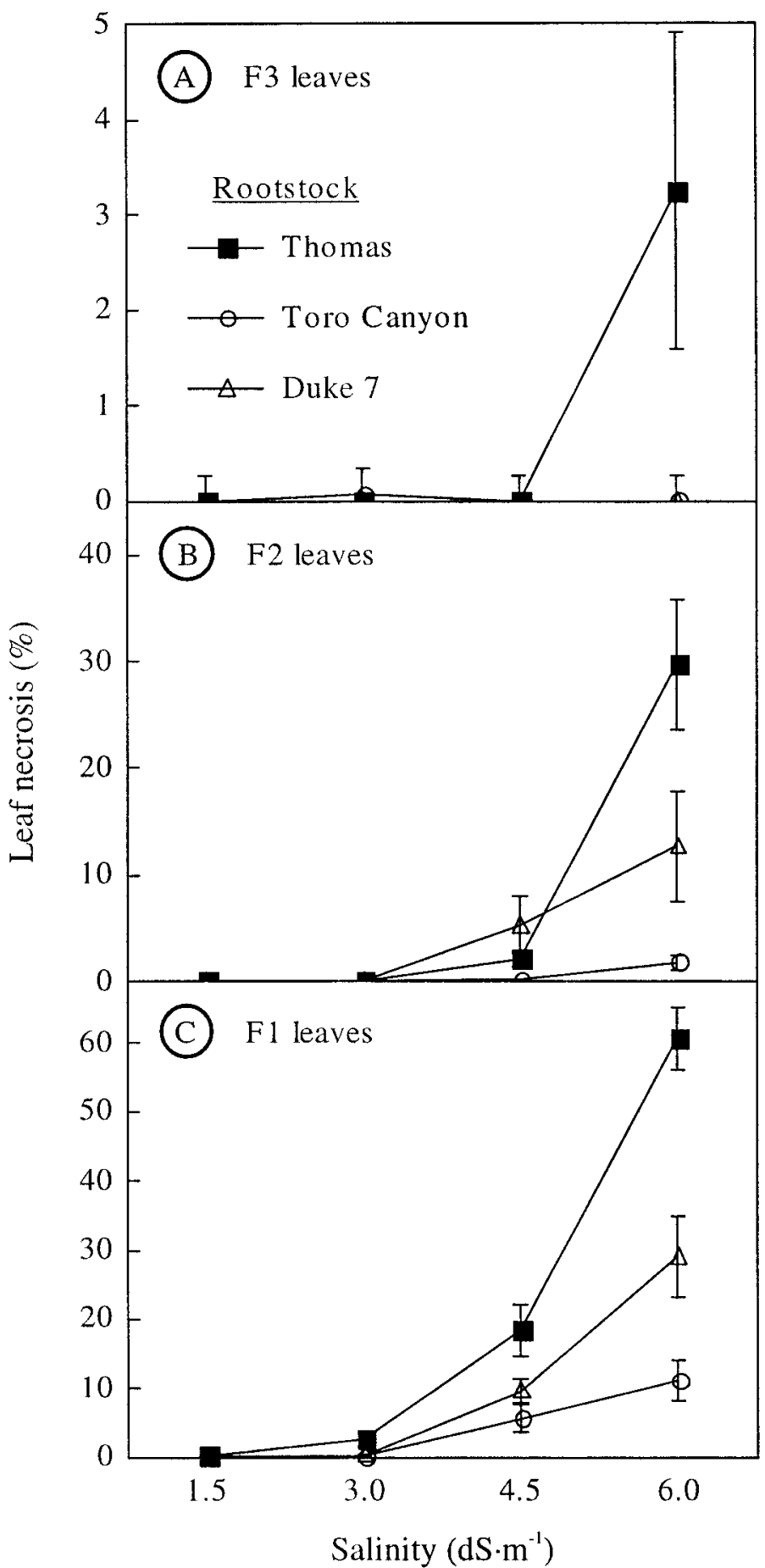

Fig. 5. Leaf necrosis of (A) F3, (B) F2, and (C) F1 leaves of 'Hass' avocado trees on 'Thomas', 'Toro Canyon', or 'Duke 7' rootstocks exposed to one of four salinity levels [1.5 (control), 3.0, 4.5 or $6.0 \mathrm{dS} \cdot \mathrm{m}^{-1}$ ] for $73 \mathrm{~d}$. Each symbol represents the mean of five replications and two subsamples per replication. Vertical bars represent SE values. Note that Y-axis scales are different among panels. necrosis with increasing salinity occurred in the TH rootstock, and leaves on TC rootstock exhibited the least amount of necrosis. It may be that concentrations of ions other than $\mathrm{Na}^{+}$or $\mathrm{Cl}^{-}$affected the amount of necrosis exhibited by the different rootstocks. At the highest salinity level, $\mathrm{F} 2$ leaves on $\mathrm{TH}$ had a $\mathrm{Na}^{+}: \mathrm{K}^{+}$ratio that was 20 and 9 times that of leaves on TC or D7, respectively (data not presented).

Injury by $\mathrm{Cl}^{-}$in avocado results in leaf tip burn, whereas $\mathrm{Na}^{+}$ injury results in interveinal necrosis (Ayers et al., 1951). All of the necrosis observed in this study was typical of $\mathrm{Cl}^{-}$injury even though $\mathrm{Na}^{+}$levels were very high in damaged leaves and were correlated with the degree of necrosis. It is possible that elevated $\mathrm{Na}^{+}$exacerbated the effects (and therefore, the visual symptoms) of the $\mathrm{Cl}^{-}$accumulated in the leaves.

Salinization resulted in decreased A of all leaves measured over time (data not presented). For most days in which A measurements were made, significant rootstock differences could not be distinguished (data not shown). However, differences in A among rootstocks due to salinity were observed on day 66 (Fig. 6). Leaves of TH exposed to salinity levels of $4.5 \mathrm{or} 6.0 \mathrm{dS} \cdot \mathrm{m}^{-1}$ had A levels that were significantly lower than those of the other two rootstocks. Differences in A corresponded to differences in

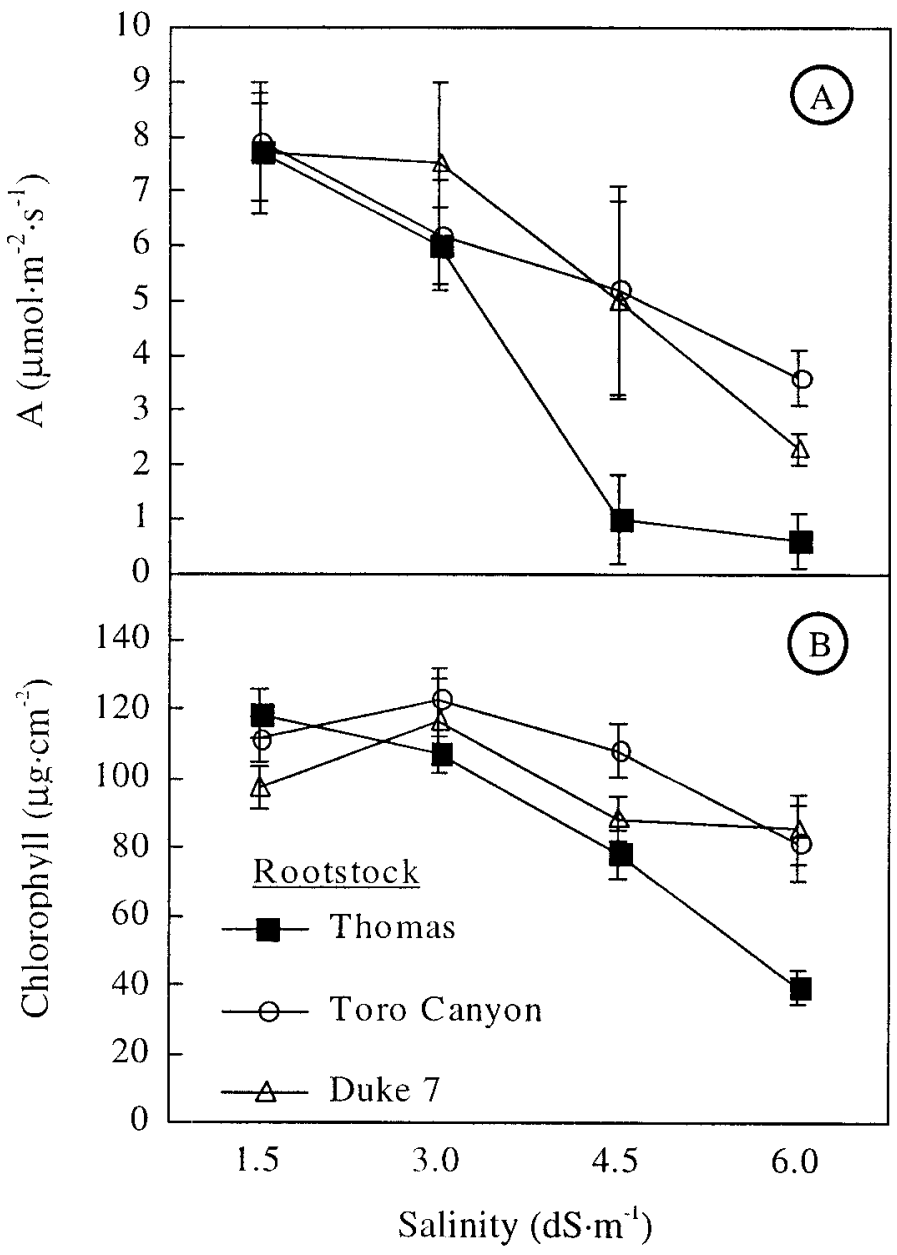

Fig. 6. (A) Net $\mathrm{CO}_{2}$ assimilation (A) and (B) chlorophyll concentrations of $\mathrm{F} 2$ leaves of 'Hass' avocado trees on 'Thomas', 'Toro Canyon', or 'Duke 7' rootstocks exposed to one of four salinity levels [1.5 (control), 3.0, 4.5 or 6.0 $\mathrm{dS} \cdot \mathrm{m}^{-1}$ ] for (A) 66 or (B) $73 \mathrm{~d}$. Each symbol represents the mean of five (shoot extension) or four (leaf area) replications and two subsamples per replication. Vertical bars represent SE values. 
chlorophyll content of the leaves (Fig. 6). Chlorophyll decreased with increased salinity in leaves on both a dry weight basis (data not presented) and on an area basis (Fig. 6). Chlorophyll a:b ratio was similar in leaves on all rootstocks and was not affected by salinity (data not presented).

Leaves of all ages on all rootstocks had decreased A when exposed to salinity (Fig. 7). F1 leaves had lower A than F2 leaves and exhibited the greatest decrease in A with increasing salinity in all rootstocks. F1 leaves on $\mathrm{TH}, \mathrm{TC}$, and D7 trees exposed to

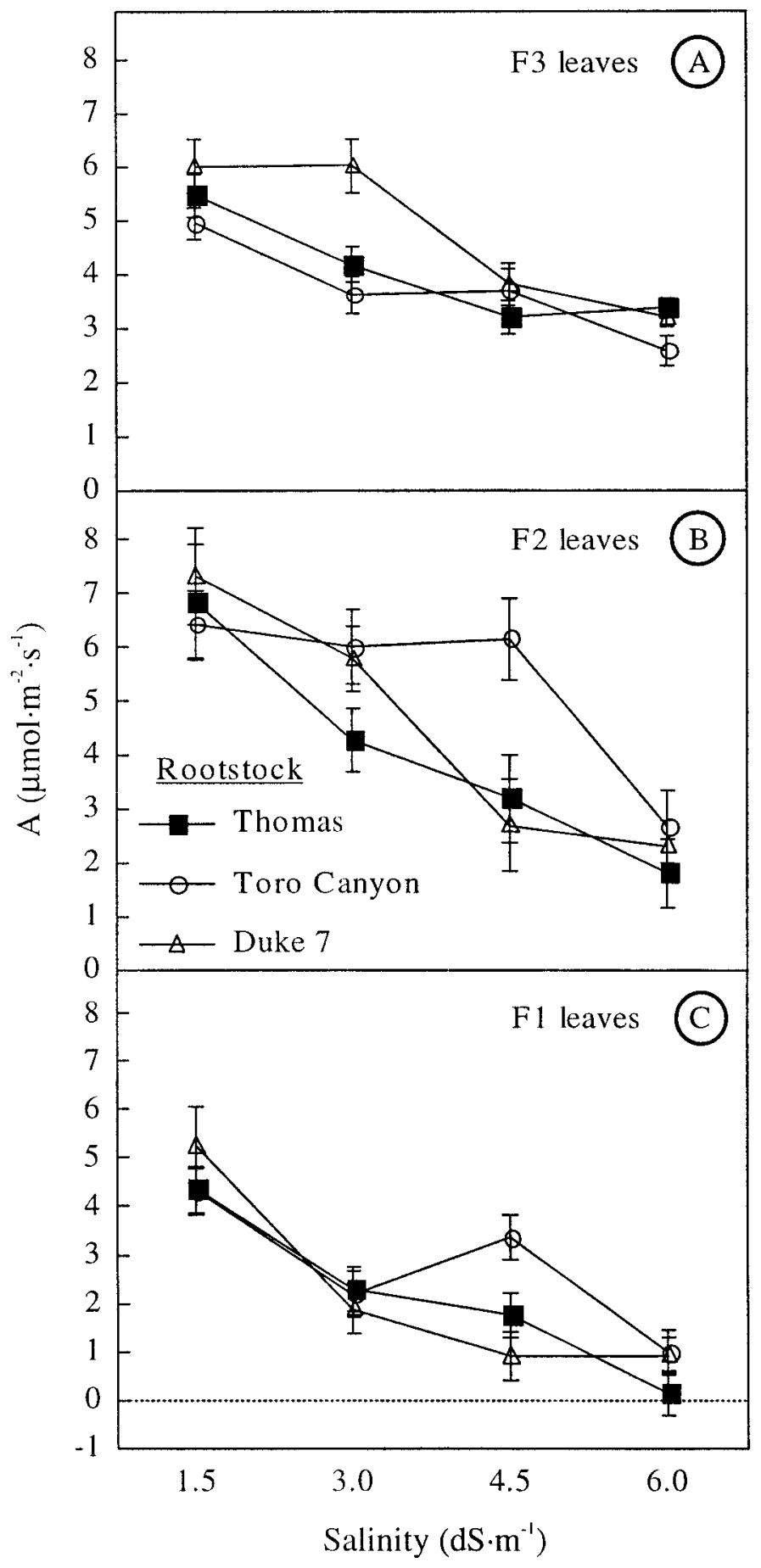

Fig. 7. Net $\mathrm{CO}_{2}$ assimilation (A) of (A) F3, (B) F2, and (C) F1 leaves of 'Hass' avocado trees on Thomas, Toro Canyon, or Duke 7 rootstocks exposed to one of four salinity levels [ 1.5 (control), $3.0,4.5$ or $6.0 \mathrm{dS} \cdot \mathrm{m}^{-1}$ ] for $73 \mathrm{~d}$. Each symbol represents the mean of five replications. Vertical bars represent SE values.
$6.0 \mathrm{dS} \cdot \mathrm{m}^{-1}$ had A rates that were $3 \%, 23 \%$, and $18 \%$ of the controls, respectively.

Behboudian et al. (1986) suggested that increased shoot $\mathrm{Na}^{+}$ was the most significant factor in determining reductions in $\mathrm{A}$ in various citrus scion-rootstock combinations. However, while a correlation between high $\mathrm{Na}^{+}$and reduced $\mathrm{A}$ are suggested in some citrus species (Walker et al., 1993), other studies implicate $\mathrm{Cl}^{-}$as having the main toxic effect on photosynthesis (Lloyd et al., 1989). Because $\mathrm{Na}^{+}$and $\mathrm{Cl}^{-}$were applied simultaneously in our study, it is difficult to determine the relative effect of either ion on physiological responses to salinity. Leaves on TH accumulated much higher $\mathrm{Na}^{+}$and $\mathrm{Cl}^{-}$than leaves on the other rootstocks and exhibited a statistically lower $\mathrm{A}$ at one point during the experiment. The effect of rootstock in mediating $\mathrm{CO}_{2}$ assimilation reductions due to salinity is most likely complex and may depend on factors other than ion sequestration. These factors are likely to include water transport and the availability of other mineral nutrients. Reductions in A may be explained in part by decreases in chlorophyll with increased salinity level (Fig. 6). The reduced chlorophyll concentration in response to increased salinity is a common occurrence in woody tree species such as citrus (Syvertsen et al., 1988; Zekri, 1991).

Numerous studies have indicated the order of salinity tolerance among avocado rootstock races to be West Indian > Guatemalan > Mexican (Cooper and Gorton, 1950; Downton, 1978; Kadman, 1960). This ranking is consistent with the results of this research and is thought to be due to the increasing ability of these rootstocks to exclude $\mathrm{Na}^{+}$(Ben-Ya'acov, 1970; Haas, 1950b, 1952) and/or $\mathrm{Cl}^{-}$(Bar et al., 1987; Embleton et al., 1955) from the leaves of scions. Although trees on TC (a Mexican-Guatemalan hybrid) had root $\mathrm{Na}^{+}$equal to that of the other rootstocks (data not presented), the above-graft $\mathrm{Na}^{+}$at high salt concentrations was much lower in TC trees than in trees on the other rootstocks. The high leaf $\mathrm{Na}^{+}$of TH leaves (Fig. 1) was similar to that reported for other Mexican rootstock varieties (Downton, 1978; Kadman, 1960). However, the other Mexican rootstock used in this study, D7, had much lower leaf $\mathrm{Na}^{+}$than that of trees on TH. A similar pattern was noted with $\mathrm{Cl}^{-}$(Fig. 2). Although the Mexican race rootstocks (TH and D7) had higher $\mathrm{Cl}^{-}$than the MexicanGuatemalan hybrid (TC), large differences were still apparent between TH and D7, even if differences in growth (Fig. 4) are considered. This is an important observation because Mexican rootstocks are often used in regions such as southern California because of their superior cold tolerance rather than the more salttolerant West Indian or Guatemalan rootstocks. The superior sequestration of $\mathrm{Na}^{+}$and $\mathrm{Cl}^{-}$(and subsequent greater salt tolerance of the scion) observed in D7 over TH may indicate a wider genetic range of salt tolerance than was previously thought to exist in the Mexican race.

In conclusion, salinity resulted in increased $\mathrm{Na}^{+}$and $\mathrm{Cl}^{-}$ concentrations of all organs, and reduced growth and photosynthesis of 'Hass' avocado grafted on three rootstocks. Of the three rootstocks used in this study, trees on $\mathrm{TH}$ had the highest concentrations of $\mathrm{Na}^{+}$and $\mathrm{Cl}^{-}$in vegetative organs and stems, and the greatest increase in leaf necrosis with increasing salinity. Overall tolerance was clearly related to the respective abilities of the observed rootstocks to exclude $\mathrm{Na}^{+}$and $\mathrm{Cl}^{-}$ions from the aboveground portions of the tree, although differences in overall vigor on the various rootstocks may play a role in the response to salinity (e.g., trees on D7). The effect of salinity on 'Hass' avocado appeared to be primarily that of reduced leaf area and shoot growth, and increased leaf necrosis. Although trees on TH 
exhibited lower A on one occasion (Fig. 6), for most of the study, differences in A among rootstocks were nonsignificant. The greater salinity tolerance of D7 compared to TH, two Mexican race rootstocks, may indicate greater genetic diversity within the Mexican race than reported previously. Finally, the best marker for determining the relative salt tolerance among these rootstocks appeared to be $\mathrm{Na}^{+}$of the young leaves (Fig. 1) and shoot tips (Fig. 3 ). This, more than any other measured variable, distinguished rootstock effects and indicated impending salinity damage.

\section{Literature Cited}

Arpaia, M.L., G.W. Witney, P.W. Robinson, and M.V. Mickelbart. 1995. 'Hass' avocado phenology in California: Preliminary results. Subtrop. Fruit News 3:1-2.

Ayers, A.D., D.G. Aldrich, and J.J. Coony. 1951. Sodium and chloride injury of Fuerte avocado leaves. Calif. Avocado Soc. Yrbk. 36:174178.

Banuls, J., F. Legaz, and E. Primo-Millo. 1990. Effect of salinity on uptake and distribution of chloride and sodium in some citrus scionrootstock combinations. J. Hort. Sci. 65:715-724.

Banuls, J. and E. Primo-Millo. 1995. Effects of salinity on some citrus scion-rootstock combinations. Ann. Bot. 76:97-102.

Bar, Y., U. Kafkafi, and E. Lahav. 1987. Nitrate nutrition as a tool to reduce chloride toxicity in avocado. S. Afr. Avocado Growers' Assn. Yrbk. 10:47-48.

Behboudian, M.H., E. Torokfalvy, and R.R. Walker. 1986. Effects of salinity on ionic content, water relations and gas exchange parameters in some citrus scion-rootstock combinations. Scientia Hort. 28:105116.

Ben-Ya'acov, A.D. 1970. Characteristics associated with salt tolerance in avocados grafted on Mexican and West Indian rootstocks. Proc. 18th Intl. Hort. Congr. vol. 1. p. 135.

Bingham, F.T. and L.B. Fenn. 1966. Chloride injury to Hass avocado trees: A sandculture experiment. Calif. Avocado Soc. Yrbk. 50:99106.

Branson, R.L. and C.D. Gustafson. 1972. Irrigation water - A major salt contributor to avocado orchards. Calif. Avocado Soc. Yrbk. 55:56-60.

Bruinsma, J. 1963. The quantitative analysis of chlorophylls a and b in plant extracts. Photochem. Photobiol. 2:241-249.

Chirachint, W. and D.W. Turner. 1988. Shade reduces the foliar symptoms of 'Fuerte' avocado affected by salt, without significantly changing the concentration of $\mathrm{Na}, \mathrm{K}$ or $\mathrm{Cl}$ in the leaves. Scientia Hort. 36:115 .

Cooper, W.C. and B.S. Gorton. 1950. Relation of leaf composition to leaf burn of avocados and other sub-tropical fruits. Texas Avocado Soc. Yrbk. 3:32-38.

Downton, W.J.S. 1978. Growth and flowering in salt-stressed avocado trees. Austral. J. Agr. Res. 29:523-534.

Embleton, T.W., M.M. Matsumura, W.B. Storey, and M.J. Garber. 1955. Chlorine and other elements in avocado leaves influenced by rootstock. J. Amer. Soc. Hort. Sci. 80:230-236.

Embleton, T.W., M.M. Matsumura, W.B. Storey, and M.J. Garber. 1961. Chloride and avocado rootstocks. Calif. Avocado Soc. Yrbk. 45:110 115.

Frankenberger, Jr., W.T., M.A. Tabatabai, D.C. Adriano, and H.E. Doner. 1996. Bromine, chlorine, and fluorine, p. 833-867. In: J.M. Bartels (ed.). Methods of soil analysis. Part 3. Chemical methods. Soil Sci. Soc. Amer., Madison, Wis.

Gustafson, C.D., A. Kadman, and A. Ben-Ya'acov. 1970. Sodium-22 distribution in inarched grafted avocado plants. Proc. 18th Intl. Hort. Cong. vol. I. p. 135.

Haas, A.R.C. 1950a. Rootstock influence on the composition of avocado scion leaves. Calif. Avocado Soc. Yrbk. 35:149-152.
Haas, A.R.C. 1950b. Effect of sodium chloride on Mexican, Guatemalan, and West Indian avocado seedlings. Calif. Avocado Soc. Yrbk. 35:153-160.

Haas, A.R.C. 1950c. Calcium in relation to the effects of sodium in avocado seedlings. Calif. Avocado Soc. Yrbk. 35:161-168.

Haas, A.R.C. 1952. Sodium effects on avocado rootstocks. Calif. Avocado Soc. Yrbk. 37:159-166.

Hoagland, D.R. and D.I. Arnon. 1950. The water-culture method of growing plants without soil. Univ. Calif. (Berkeley) College of Agr. Circ. 347.

Jones, Jr., J.B. 1984. A laboratory guide of exercises in conducting soil tests and plant analyses. Benton Laboratories, Inc. Athens, Ga.

Kadman, A. 1958. The uptake and accumulation of chloride in avocado leaves and the tolerance of avocado seedlings under saline conditions. J. Amer. Soc. Hort. Sci. 83:280-286.

Kadman, A. 1960. The uptake and accumulation of sodium in avocado seedlings. J. Amer. Soc. Hort. Sci. 85:179-182.

Kalmar, D. and E. Lahav. 1977. Water requirements of avocado in Israel. I. Tree and soil parameters. Austral. J. Agr. Res. 28:859-868.

Lahav, E. and D. Kalmar. 1977. Water requirements of avocado in Israel. II. Influence on yield, fruit growth and oil content. Austral. J. Agr. Res. 28:869-877.

Lloyd, J., P.E. Kriedemann, and D. Aspinall. 1989. Comparative sensitivity of 'Prior Lisbon' lemon and 'Valencia' orange trees to foliar sodium and chloride concentrations. Plant Cell Environ. 12:529-540.

Lloyd, J., J.P. Syvertsen, and P.E. Kriedemann. 1987. Salinity effects on leaf water relations and gas exchange of 'Valencia' orange, Citrus sinensis (L.) Osbeck, on rootstocks with different salt exclusion characteristics. Austral. J. Plant Physiol. 14:605-617.

Maas, E.V. 1986. Salt tolerance of plants. Appl. Agr. Res. 1:12-26.

Moore, P.W. and S.J. Richards. 1946. Effects of irrigation treatments and rates of nitrogen fertilization on young Hass avocado trees. II. Relation to leaf tipburn, tree sunburn, shoot dieback, leaf scorch, leaf color, leaf size, tree vigor, and leaf moisture deficits. Proc. Amer. Soc. Hort. Sci. 71:298-303.

Oster, J.D. and M.L. Arpaia. 1992. 'Hass' avocado response to salinity as influenced by clonal rootstocks, p. 209-214. In: C. Lovatt (ed.). Proc. 2nd World Avocado Congr., Orange, Calif., 21-26 Apr. 1991.

Oster, J.D., R. Brokaw, R.A. Strohman, and J.E. Tracy. 1985. The influence of salinity and rootstock on avocado seedling growthProgress report. Calif. Avocado Soc. Yrbk. 69:105-110.

SAS Institute, Inc. 1985. SAS user's guide: Statistics. 5th ed. SAS Inst., Inc., Cary, N.C.

Schaffer, B., A.W. Whiley, and R.R. Kohli. 1991. Effects of leaf age on gas exchange characteristics of avocado (Persea americana Mill.). Scientia Hort. 48:21-28.

Syvertsen, J.P., J. Lloyd, and P.E. Kriedemann. 1988. Salinity and drought stress effects on foliar ion concentration, water relations, and photosynthetic characteristics of orchard citrus. Austral. J. Agr. Res. 39:619-627.

Walker, R.R., D.H. Blackmore, and S. Qing. 1993. Carbon dioxide assimilation and foliar ion concentrations in leaves of lemon (Citrus limon L.) trees irrigated with $\mathrm{NaCl}$ or $\mathrm{Na}_{2} \mathrm{SO}_{4}$. Austral. J. Plant Physiol. 20:173-185.

Whiley, A.W., J.B. Saranah, B.W. Cull, and K.G. Pegg. 1988. Manage avocado tree growth cycles for productivity gains. Queensland Agr. J. 114:29-36.

Whitsell, R.H., G.E. Martin, B.O. Bergh, A.V. Lypps, and W.H. Brokaw. 1989. Propagating avocados: Principles and techniques of nursery and field grafting. Univ. Calif. Div. Agr. and Natural Resources Publ. 21461.

Wiesman, Z. 1995. Rootstock and nitrate involvement in 'Ettinger' avocado response to chloride stress. Scientia Hort. 62:33-43.

Zekri, M. 1991. Effects of $\mathrm{NaCl}$ on growth and physiology of sour orange and Cleopatra mandarin seedlings. Scientia Hort. 47:305-315. 